\title{
A Comparative Study of DTC-SVM and FOC-SVM Control Techniques of Induction Motor Drive
}

\author{
${ }^{1}$ Dalya H. Al-Mamoori, ${ }^{1}$ Zaid H. Al-Tameemi, ${ }^{1}$ Fadhel A. Jumaa, \\ ${ }^{1}$ Omar Muhammed Neda and ${ }^{2}$ Malik G. Al-Ghanimi \\ ${ }^{1}$ Department of Electrical Power Engineering, \\ ${ }^{2}$ Technical Institute of Al-Mussaib, Department of Engineering, \\ Al-Furat Al-Awsat Technical University, Najaf, Iraq
}

\begin{abstract}
The Direct Control (DTC) technique is deemed as one of the important control techniques that have been utilising in induction motors in order to achieve a high-speed response as well as fast torque response. Conversely, the classical DTC has some main drawbacks including a high level of torque ripple and stator current harmonics. Therefore, this study presents a DTC method coupled with space vector modulation based on the reference flux and torque to overcome such issues. In this projected control method, PI torque and PI flux controllers have been designed in order to compare an estimated flux and torque responses with reference flux and torque, respectively. This proposed technique has been compared with Field Oriented Control (FOC) technique to comprehend the impact of each technique on induction motor drives. DTC-SVM and FOC have been implemented by using a MATLAB Software package to simulate induction motor dynamics to produce findings for evaluation. The ostensible comparison of both techniques is shown with the simulation results.
\end{abstract}

Key words: FOC control, DTC control, SVM technique, PI controller, PI torque, PI flux

\section{INTRODUCTION}

Induction motor drives are presently employed in various industrial, commercial, residential applications due to their robustness, fewer maintenance necessities and high-speed operation. During the last few decades an assortment of control methods has been fabricated to increase the performance of induction motor such as FOC and DTC techniques (Cruz et al., 2004). These methods have different principle operation to achieve the same control objectives (Zhu et al., 2013). Both methods depend upon the decoupling between current components utilised for producing torque and magnetising flux which can allow of the induction motor to be controlled as DC motor (Mesloub et al., 2016). In 1986, Takahashi presented a new control technique based on replacing the motor decoupling via. hysteresis controllers that have a similar operation as inverter semiconductor power devices. This strategy is called DTC (Hiba et al., 2013). However, some defects were observed through using the classical DTC such as torque, flux and stator currents ripple during steady and transient states which can impact adversely on speed estimation as well as it can cause harmonics losses and undesirable noise (Casadei et al., 2002). Therefore, the current study aimed to propose DTC-SVC based on two PI speed controllers to eliminate such issues. In this technique, the stator currents, flux and torque have low ripples as compared with a classical one. The simulation results of DTC-SVM method are compared with the FOC ones to identify two methods influence on the behaviour of the respective induction motor drives.

\section{MATERIALS AND METHODS}

Principles of DTC and FOC techniques: DTC method is classified as the most modern method based on the field oriented control and the direct self-control scheme which has been realised industrially by Depenbrok between 1971-1985 (Popescu, 2000; Eason et al., 1955). The main concept of this technique is to control stator flux and the torque by choosing the voltage space vectors appropriately via. a hysteresis controller as well as a switching table (Takahashi and Noguchi, 1986; El-Ouanjli et al., 2017). The classical DTC scheme has various disadvantages including variable switching frequency, a high level of torque and current ripples and slow speed response. Furthermore, it is required a high frequency for digital execution of the hysteresis controllers. In order to overcome such

Corresponding Author: Dalya H. Al-Mamoori, Department of Electrical Power Engineering,

Al-Furat Al-Awsat Technical University, Najaf, Iraq 
issues, DTC-SVM is proposed in this study to provide a fixed switching frequency (El-Laban et al., 2006; Zaid et al., 2010). In the DTC-SVM structure, flux and torque hysteresis controllers are substituted with PI controller to adjust the magnitude value of torque and flux, respectively. These PI controllers are employed to produce $\mathrm{d}-\mathrm{q}$ components of the $\mathrm{I} / \mathrm{P}$ voltage that will be commended for the inverter which can confirm the switching frequency of the inverter to be constant. It is observed that an increase in the switching frequency contributes to dramatically decreasing the undesirable current harmonics and the torque ripples as compared with the conventional DTC scheme (Zaid et al., 2010). The DTC-SVM of the induction motor is described by the simple blocks as elucidated in the Fig. 1.

Filed oriented control has been invented at the beginning of $1970 \mathrm{sec}$. It shows that induction motors can be controlled like excited DC motor separately as well as it contributed to bringing a revitalization in the high-performance control of $\mathrm{AC}$ motors. It is worth mentioning that filed oriented control technique applies to both induction and synchronous motors (Kaewjinda and Konghirun, 2007). The principle operation of a vector control technique is to control the stator flux and torque of a respective, motor independently through influencing the related field oriented quantities. The block diagram of the FOC technique of induction motor is demonstrated in Fig. 2.

Modelling of induction motor via. DTC-SVM and FOC-SVM methods: Reference frame theory is most widely used in mathematical modelling of DCT-SVM and FOC-SVM of induction motor to convert from three-phase quantities (abc) to the two-phase quantities (dq) is required in order to facilitate the analysis in the setting of position or speed and also in order 3-phase induction motor has a behaviour resembles the DC motor and thus more easily controlled. Convert from three-phase system to dq axis system by park's transformation can be written in matrix form:

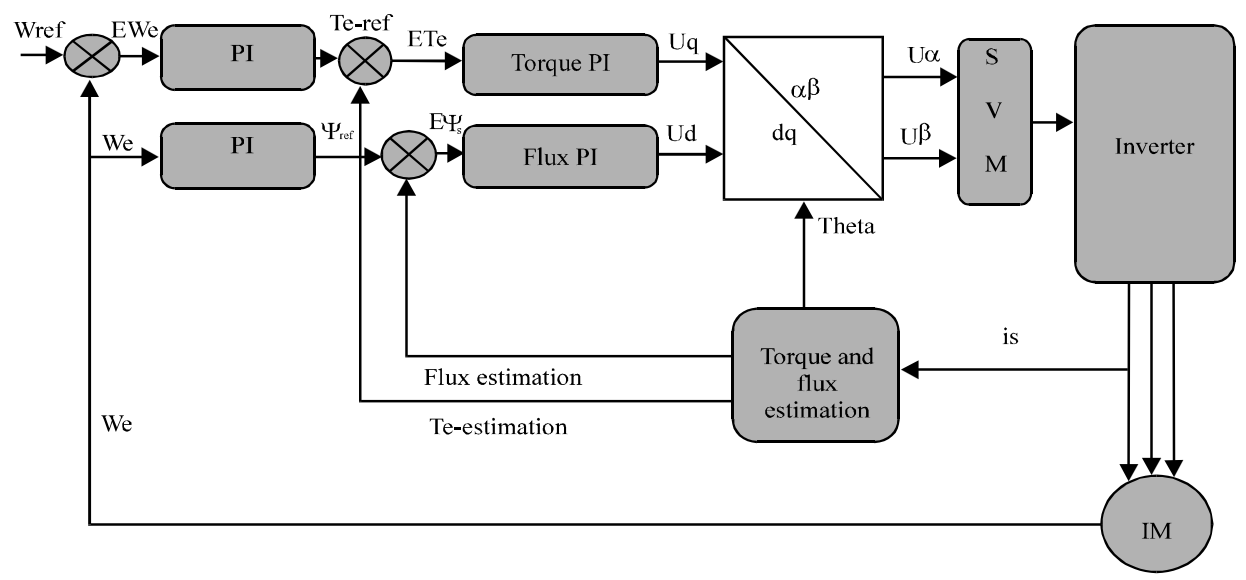

Fig. 1: Block diagram of DTC control

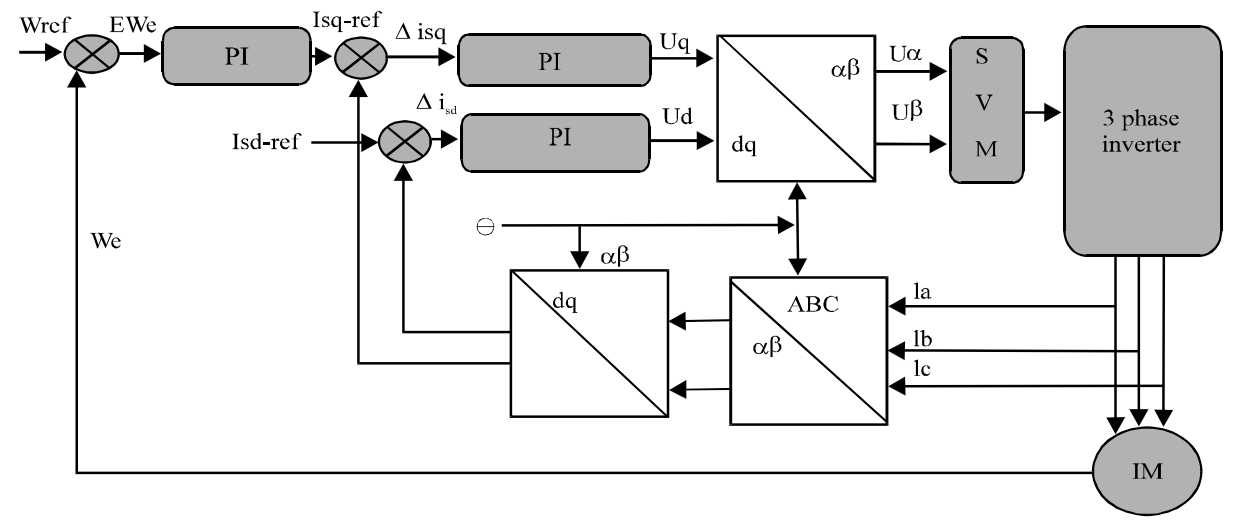

Fig. 2: Block diagram of the FOC control 
$\left[\begin{array}{c}\mathrm{V}_{\mathrm{d}} \\ \mathrm{V}_{\mathrm{q}}\end{array}\right]=\frac{2}{3}\left[\begin{array}{ccc}1 & -\frac{1}{2} & -\frac{1}{2} \\ 0 & \frac{\sqrt{3}}{2} & -\frac{\sqrt{3}}{2}\end{array}\right]\left[\begin{array}{c}\mathrm{V}_{\mathrm{an}} \\ \mathrm{V}_{\mathrm{bn}} \\ \mathrm{V}_{\mathrm{cn}}\end{array}\right]\left[\begin{array}{c}\mathrm{V}_{\mathrm{d}} \\ \mathrm{V}_{\mathrm{q}}\end{array}\right]=\frac{2}{3}\left[\begin{array}{ccc}1 & -\frac{1}{2} & -\frac{1}{2} \\ 0 & \frac{\sqrt{3}}{2} & -\frac{\sqrt{3}}{2}\end{array}\right]\left[\begin{array}{c}\mathrm{V}_{\mathrm{an}} \\ \mathrm{V}_{\mathrm{bn}} \\ \mathrm{V}_{\mathrm{cn}}\end{array}\right]$

The voltage equation of $\mathrm{dq}$ axis can be written as follows:

$$
\begin{gathered}
\mathrm{V}_{\mathrm{ds}}=\mathrm{R}_{\mathrm{s}} \cdot \mathrm{I}_{\mathrm{ds}}-\omega \mathrm{e} \psi_{\mathrm{qs}} \mathrm{V}_{\mathrm{ds}}=\mathrm{R}_{\mathrm{s}} \cdot \mathrm{I}_{\mathrm{ds}}-\omega \mathrm{e} \psi_{\mathrm{qs}} \\
\mathrm{V}_{\mathrm{qs}}=\mathrm{R}_{\mathrm{s}} \mathrm{I}_{\mathrm{qs}}+\omega \mathrm{e} \cdot \psi_{\mathrm{ds}} \mathrm{V}_{\mathrm{qs}}=\mathrm{R}_{\mathrm{s}} \cdot \mathrm{I}_{\mathrm{qs}}+\omega \mathrm{e} \cdot \psi_{\mathrm{ds}} \\
\mathrm{V}_{\mathrm{dr}}{ }^{\prime}=\mathrm{R}_{\mathrm{r}}{ }^{\prime} \mathrm{I}_{\mathrm{dr}}{ }^{\prime}+(\omega-\omega \mathrm{e}) \psi_{\mathrm{qr}}{ }^{\prime} \mathrm{V}_{\mathrm{dr}}{ }^{\prime}=\mathrm{R}_{\mathrm{r}}{ }^{\prime} \cdot \mathrm{I}_{\mathrm{dr}}{ }^{\prime}+(\omega-\omega \mathrm{e}) \psi_{\mathrm{qr}}{ }^{\prime} \\
\mathrm{V}_{\mathrm{dr}}{ }^{\prime}=\mathrm{R}_{\mathrm{r}}{ }^{\prime} \cdot \mathrm{I}_{\mathrm{dr}}{ }^{\prime}-(\omega-\omega \mathrm{e}) \psi_{\mathrm{qr}}{ }^{\prime} \mathrm{V}_{\mathrm{dr}}{ }^{\prime}=\mathrm{R}_{\mathrm{r}}{ }^{\prime} \cdot \mathrm{I}_{\mathrm{dr}}{ }^{\prime}-(\omega-\omega \mathrm{e}) \psi_{\mathrm{qr}}{ }^{\prime}
\end{gathered}
$$

where, the flux linkages:

$$
\begin{aligned}
& {\left[\begin{array}{l}
\psi_{\mathrm{ds}} \\
\psi_{\mathrm{qs}}
\end{array}\right]=\mathrm{L}_{\mathrm{s}} \cdot\left[\begin{array}{c}
\mathrm{I}_{\mathrm{ds}} \\
\mathrm{I}_{\mathrm{qs}}
\end{array}\right]+\mathrm{L}_{\mathrm{h}}\left[\begin{array}{c}
\mathrm{I}_{\mathrm{dr}}{ }^{\prime}{ }^{\prime} \\
\mathrm{I}_{\mathrm{qr}}{ }^{\prime}
\end{array}\right]\left[\begin{array}{l}
\psi_{\mathrm{ds}} \\
\psi_{\mathrm{qs}}
\end{array}\right]=\mathrm{L}_{\mathrm{s}} \cdot\left[\begin{array}{c}
\mathrm{I}_{\mathrm{ds}} \\
\mathrm{I}_{\mathrm{qs}}
\end{array}\right]+} \\
& \mathrm{L}_{\mathrm{h}}\left[\begin{array}{c}
\mathrm{I}_{\mathrm{dr}}{ }^{\prime} \\
\mathrm{I}_{\mathrm{qr}}{ }^{\prime}
\end{array}\right]\left[\begin{array}{c}
\psi_{\mathrm{dr}}^{\prime} \\
\psi_{\mathrm{qr}}^{\prime}
\end{array}\right]=\mathrm{L}_{\mathrm{r}}{ }^{\prime} \cdot\left[\begin{array}{c}
\mathrm{I}_{\mathrm{dr}}{ }^{\prime} \\
\mathrm{I}_{\mathrm{qr}}{ }^{\prime}
\end{array}\right]+\mathrm{L}_{\mathrm{h}}\left[\begin{array}{c}
\mathrm{I}_{\mathrm{ds}} \\
\mathrm{I}_{\mathrm{qs}}
\end{array}\right]\left[\begin{array}{c}
\psi_{\mathrm{dr}}{ }^{\prime} \\
\psi_{\mathrm{qr}}^{\prime}
\end{array}\right]= \\
& \mathrm{L}_{\mathrm{r}}{ }^{\prime} \cdot\left[\begin{array}{c}
\mathrm{I}_{\mathrm{dr}}{ }^{\prime} \\
\mathrm{I}_{\mathrm{qr}}{ }^{\prime}
\end{array}\right]+\mathrm{L}_{\mathrm{h}}\left[\begin{array}{c}
\mathrm{I}_{\mathrm{ds}} \\
\mathrm{I}_{\mathrm{qs}}
\end{array}\right]
\end{aligned}
$$

The stator Flux linkages and electromagnetic torque equations can be re-written from the above voltage equations as follows:

$$
\begin{aligned}
& \frac{\Psi_{\mathrm{ds}}}{\mathrm{dt}}=\mathrm{V}_{\mathrm{qs}}-\mathrm{R}_{\mathrm{s}} \cdot \mathrm{I}_{\mathrm{qs}} \frac{\Psi_{\mathrm{ds}}}{\mathrm{dt}}=\mathrm{V}_{\mathrm{qs}}-\mathrm{R}_{\mathrm{s}} \cdot \mathrm{I}_{\mathrm{qs}} \\
& \frac{\Psi_{\mathrm{qs}}}{\mathrm{dt}}=\mathrm{V}_{\mathrm{ds}}-\mathrm{R}_{\mathrm{s}} \cdot \mathrm{I}_{\mathrm{ds}} \frac{\Psi_{\mathrm{qs}}}{\mathrm{dt}}=\mathrm{V}_{\mathrm{ds}}-\mathrm{R}_{\mathrm{s}} \cdot \mathrm{I}_{\mathrm{ds}}
\end{aligned}
$$

The phase angle and the magnitude of stator flux in dq axis could be expressed as follows:

$$
\begin{gathered}
\psi_{\mathrm{s}}=\psi_{\mathrm{ds}}+\mathrm{j} \psi_{\mathrm{qs}} \psi_{\mathrm{s}}=\psi_{\mathrm{ds}}+\mathrm{j} \psi_{\mathrm{qs}} \\
\left|\psi_{\mathrm{est}}\right|=\sqrt{{\psi_{\mathrm{ds}}{ }^{2}+\psi_{\mathrm{qs}}{ }^{2}}}\left|\psi_{\text {est }}\right|=\sqrt{\psi_{\mathrm{ds}}{ }^{2}+\psi_{\mathrm{qs}}{ }^{2}} \\
\theta=\tan ^{-1} \frac{\psi_{\mathrm{qs}}}{\psi_{\mathrm{ds}}} \theta=\tan ^{-1} \frac{\psi_{\mathrm{qs}}}{\psi_{\mathrm{ds}}}
\end{gathered}
$$

The electromagnetic torque of the induction motor is obtained from stator flux linkages and stator currents in $\mathrm{dq}$ axis. The stator flux linkages are obtaining from inductance and stator current in dq axis.

$$
\mathrm{T}_{\mathrm{e}}=3 / 4 \mathrm{P}\left(\psi_{\mathrm{ds}}, \mathrm{I}_{\mathrm{qs}}-\psi_{\mathrm{qs}} \cdot \mathrm{I}_{\mathrm{ds}}\right) \mathrm{T}_{\mathrm{e}}=3 / 4 \mathrm{P}\left(\psi_{\mathrm{ds}} \cdot \mathrm{I}_{\mathrm{qs}}-\psi_{\mathrm{qs}} \cdot \mathrm{I}_{\mathrm{ds}}\right)
$$

The electromagnetic torque of the respective, induction motor in terms of rotor speed may be expressed as follows:

$$
\mathrm{T}_{\mathrm{e}}=3 / 4 \mathrm{P}\left(\psi_{\mathrm{ds}} \cdot \mathrm{I}_{\mathrm{qs}}-\psi_{\mathrm{qs}} \cdot \mathrm{I}_{\mathrm{ds}}\right) \mathrm{T}=\mathrm{T}_{\mathrm{e}}-\mathrm{T}_{\mathrm{w}}=\frac{\mathrm{J}}{\mathrm{p}} \cdot \frac{\mathrm{d} \omega}{\mathrm{dt}}+\omega_{\mathrm{r}}
$$

The electromagnetic torque of the induction motor in terms of rotor speed can be expressed as follow:

$$
\mathrm{T}=\mathrm{T}_{\mathrm{e}}-\mathrm{T}_{\mathrm{w}}=\frac{\mathrm{J}}{\mathrm{p}} \cdot \frac{\mathrm{d} \omega}{\mathrm{dt}}+\mathrm{B} \omega_{\mathrm{r}} \mathrm{T}=\mathrm{T}_{\mathrm{e}}-\mathrm{T}_{\mathrm{w}}=\frac{\mathrm{J}}{\mathrm{p}} \cdot \frac{\mathrm{d} \omega}{\mathrm{dt}}+\mathrm{B} \omega_{\mathrm{r}}
$$

\section{RESULTS AND DISCUSSION}

This section mainly focused on the simulation and comparison between the two control methods discussed above which named as DTC-SVM and FOC-SVM. MATLAB/Simulink environment was used in order to compare and test these two approaches applied to the three-phase induction motor. The results to be presented were obtained by simulating an induction motor driver described in Table 1. Two operation modes had been considered: a constant-load start and the robustness of the control tested at the variation in load torque.

System response at constant speed and constant load torque: Figure 3 demonstrates the responses of the stator currents, rotor speed in addition to the electromagnetic

\begin{tabular}{ll} 
Table 1: Parameters of the investigated induction motor & \\
\hline Parameters & Values/units \\
\hline DC voltage & $540(\mathrm{~V})$ \\
Rated torque & $20(\mathrm{~nm})$ \\
Rated stator flux & $0.9(\mathrm{~Wb})$ \\
Rated power & $6.0(\mathrm{~kW})$ \\
Rated voltage & $380(\mathrm{~V})$ \\
Rated frequency & $50(\mathrm{~Hz})$ \\
Rated speed & $2860(\mathrm{rpm})$ \\
Stator inductance & $0.175(\mathrm{H})$ \\
Stator resistance & $3.126(\Omega)$ \\
Rotor inductance & $0.175(\mathrm{H})$ \\
Rotor resistance & $1.879(\Omega)$ \\
Mutual inductance & $0.1(\mathrm{H})$ \\
Moment inertia & $0.062\left(\mathrm{~kg} \cdot \mathrm{m}^{2}\right)$ \\
Pole pairs & 1 \\
\hline
\end{tabular}



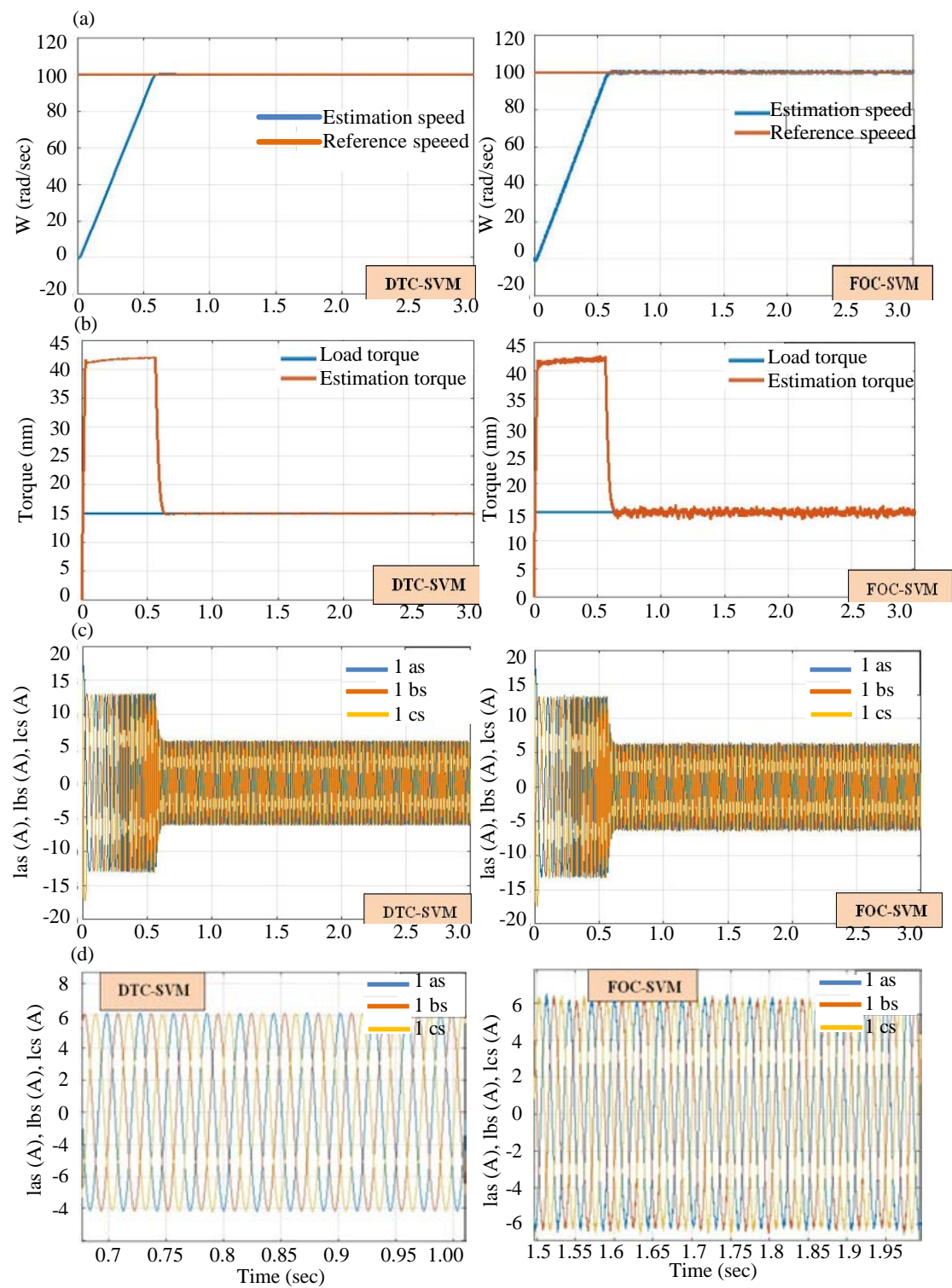

Fig. 3: Dynamic performance of induction motor using DTC-SVM and FOC-SVM at a constant speed and load torque in terms of: a) Speed; b) Torque and c, d) Stator currents

torque under steady-state conditions for nominal reference values of the machine, $15 \mathrm{~nm}$ for the torque and a reference value of flux equal to $0.9 \mathrm{wb}$. The shape of the stator currents is sinusoidal with very low ripples as compared with FOC-SVM. Thus, the operation is practically constant flux.

\section{System response when sudden change in load torque:} Figure 4 demonstrates the responses of the torque and the stator currents in the order of torque from $10-20 \mathrm{~nm}$ at reference speed $100 \mathrm{rad} / \mathrm{sec}$. The stator currents are very low ripples at the setpoint change which leads us to consider an appropriate limitation for monitoring peak currents supported by the inverter as compared with FOC-SVM. Also, it has been noted the stator currents trajectory is sinusoidal corresponds to the variations load torque. It is also possible to observe, under the same conditions that the latter in the transition stage is established rapidly which shows that the torque accurately follows its reference value and show the response time is very reliable. There is a marked improvement in harmonic terms with the DTC-SVM approach. However, the control makes it possible to illustrate a speedy response time in particular, quantities such as torque and current while remaining within the operating limit of the system but there is a reduction in 

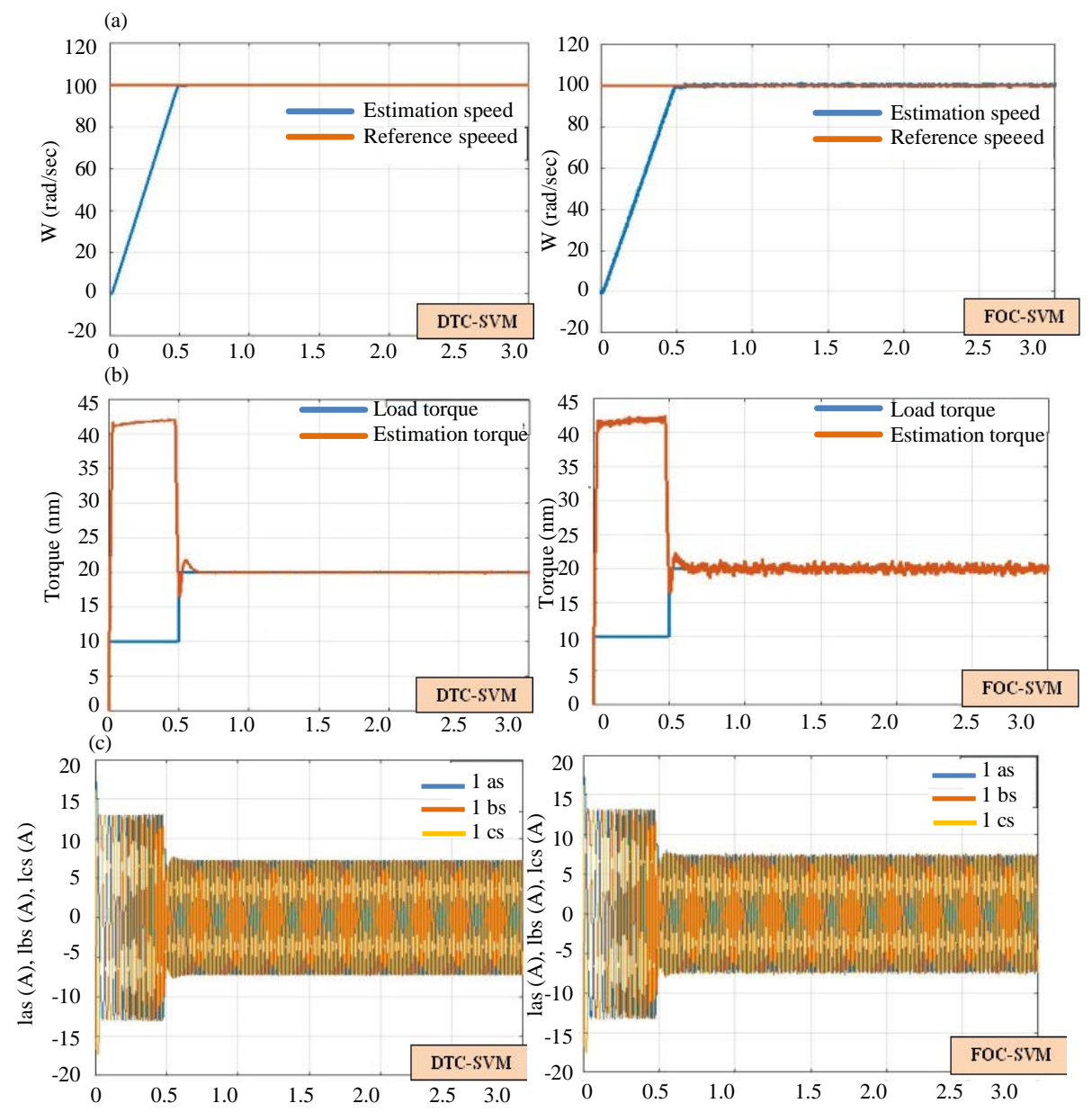

(d)
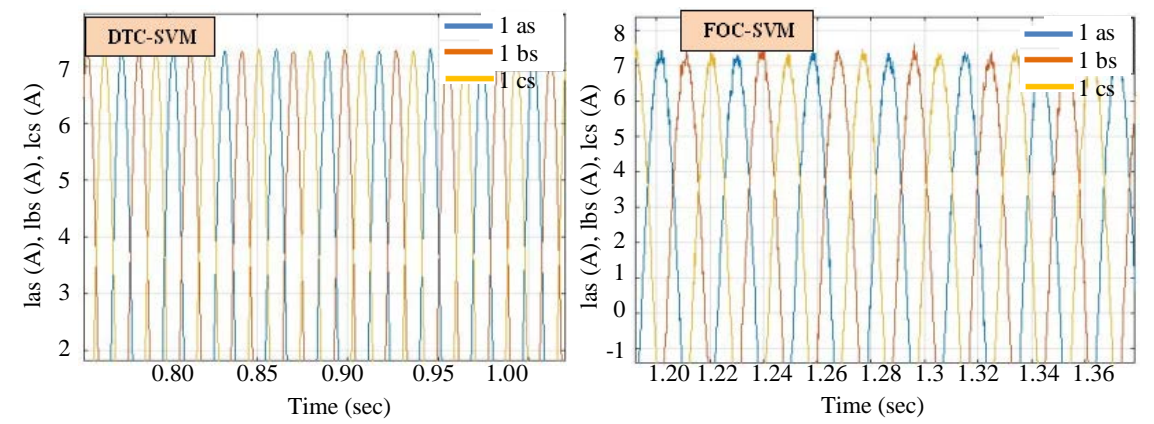

Fig. 4: Dynamic performance of induction motor using DTC-SVM and FOC-SVM at variable-load torque in terms of: a) Speed: b) Torque and c, d) Stator currents

terms of the THD with the power supply of the induction motor based a two-level voltage inverter as compared with FOC-SVM.

\section{CONCLUSION}

This study presented a reasonable comparison between different control techniques of the induction motors including FOC and DTC methods coupled with space vector modulation. Both techniques have been simulated in MATLAB/Simulink environment. By analysing the results obtained with the two control methods it can be concluding that the DTC strategy has shown an appreciable performance in a reduction ripples for both torque and stator currents. It also shows an excellent dynamic response of speed and 
good trajectory tracking. Tests performed on the observer, the change parameters and the sudden change of load have proved that the DTC-SVM control is reliable.

\section{REFERENCES}

Casadei, D., F. Profumo, G. Serra and A. Tani, 2002. FOC and DTC: Two viable schemes for induction motors torque control. IEEE Trans. Power Electron., 17: 779-787.

Cruz, C., M.A. Gallegos, R. Alvarez and F. Pazos, 2004. Comparison of several nonlinear controllers for induction motors. Proceedings of the 9th IEEE International Conference on Power Electronics Congress (CIEP 2004), October 17-22, 2004, IEEE, Celaya, Gto., Mexico, Mexico, pp: 134-139.

Eason, G., B. Noble and I.N. Sneddon, 1955. On certain integrals of Lipschitz-Hankel type involving products of Bessel functions. Phil. Trans. R. Soc. Lond. A., 247: 529-551.

El Ouanjli, N., A. Derouich, A. El Ghzizal, A. Chebabhi and M. Taoussi, 2017. A comparative study between FOC and DTC control of the Doubly Fed Induction Motor (DFIM). Proceedings of the 2017 International Conference on Electrical and Information Technologies (ICEIT'17), November 15-18, 2017, EEE, Rabat, Morocco, ISBN:978-1-5386-1517-1, pp: 1-6.

El-Laban, O.S., H.A. Fattah, H.M. Emara and A.F. Sakr, 2006. Particle swarm optimized direct torque control of induction motors. Proceedings of the IECON 2006-32nd Annual Conference on IEEE Industrial Electronics, November 6-10, 2006, IEEE, Paris, France, pp: 1586-1591.
Hiba, H., H. Ali and H. Othmen, 2013. DTC-SVM control for three phase induction motors. Proceedings of the 2013 International Conference on Electrical Engineering and Software Applications (ICEESA), March 21-23, 2013, IEEE, Hammamet, Tunisia, ISBN: 978-1-4673-6302-0, pp: 1-7.

Kaewjinda, W. and M. Konghirun, 2007. Vector control drive of permanent magnet synchronous motor using resolver sensor. ECTI. Trans. Electr. ENG. Electron. Commun., 5: 134-138.

Mesloub, H., M.T. Benchouia, A. Golea, N. Golea and M.E.H. Benbouzid, 2016. Predictive DTC schemes with PI regulator and particle swarm optimization for PMSM drive: Comparative simulation and experimental study. Intl. J. Adv. Manuf. Technol., 86: 3123-3134.

Popescu, M., 2000. Induction motor modelling for vector control purposes. MSc Thesis, Department of Electrical and Communications Engineering, Helsinki University of Technology, University in Espoo, Finland.

Takahashi, I. and T. Noguchi, 1986. A new quick-response and high efficiency control strategy of an induction machine. IEEE Trans. Ind. Appl., IA-22: 820-827.

Zaid, S.A., O.A. Mahgoub and K.A. El-Metwally, 2010. Implementation of a new fast direct torque control algorithm for induction motor drives. IET. Electr. Power Appl., 4: 305-313.

Zhu, J., X. Wang, B. Xu, H. Feng and X. Xu, 2013. A comparative study on field oriented control and direct torque control for permanent magnet linear synchronous motor. J. Comput., 8: 256-263. 